\title{
The Mobile Formal and Informal Learning for Guangzhou's University Students
}

\author{
Hugo Chun Hung Wong \\ Youth College, Hong Kong Special Administrative Region
}

\begin{abstract}
Today, mobile devices are important tools for students' daily life. They use a mobile device for communicating, playing, reading, photo shooting, learning, etc.. Therefore, this study used a qualitative approach to explore the practice and stratrgies of mobile formal and informal learning for university students studying at Guangzhou based on a theoretical model of the Framework for the Rational Analysis of Mobile Education (FRAME) model. Fourteen Guangzhou's university students were invited to participate pre-focus group interviews, diaries, and post-interview from April to June of 2013. The results find that the ratio of using a mobile device for informal learning is higher than formal learning and provides the strategies of using mobile devices in formal and informal learning of Guangzhou's university students. Therefore, teachers may design mobile learning (m-learning) and teaching activities for students based on the findings of this study. However, the findings provide good examples of using mobile devices for formal and informal learning.
\end{abstract}

Keywords: mobile learning (m-learning), formal and informal learning, Framework for the Rational Analysis of Mobile Education (FRAME) model

\section{Introduction}

Today, mobile technology has developed rapidly. Mobile technology does not only affect the way that people communicate, such as voice communication in an instant message, but also affects people's daily life. Therefore, the development of mobile technology had changed the landscape of education (Huang, Yang, Huang, \& Hsiao, 2010; Liu, Yu, \& Ran, 2008). Traxler (2007) believed that mobile learning (m-learning) is going to facilitate a wide variety of teaching methods in future. The integrated technology can engage in students' multiple learning styles (Naimie, Siraj, Abuzaid, \& Shagholi, 2010). Zywno and Waalen (2002) confirmed that multimedia in learning and taught packages enhanced academic performance in students' across learning styles. Therefore, investigation of how to use a mobile device for formal learning (Sharples, Taylor, \& Vavoula, 2005; Traxler, 2007) and informal learning (Börner, Glahn, \& Specht, 2009) has become a popular research topic, because m-learning has the greater potential for expanding learning opportunities to larger segments of the community than traditional board and chalk learning or other types of electronic learning (e-learning). Moreover, many of Chinese scholars investigate how to use mobile devices for teaching and learning (Tang, Wang, Dai, \& Zhao, 2014; Sun, Zhang, \& Wang, 2013; Zhang, Wang, Zhang, \& Di, 2010; Li, Ma, Ning, \& Li, 2012; Yang, 2013; Helen \& Peng, 2013; Wang, Xu, Zhong, \& Li, 2013; Fan, 2012; Chen, 2013), because China ranked first with respect to the number of netizens and mobile netizens in the world, and

Hugo Chun Hung Wong, Ed.D., lecturer, The Vocational Training Council, Youth College. 
more and more netizens are using a mobile rather than a personal computer.

This study would like to find out the strategies and practices of using mobile devices for formal and informal learning of Guangzhou's university students based on a theoretical model of the Framework for the Rational Analysis of Mobile Education (FRAME) model. The FRAME model took the technical features of mobile devices as well as social and personal aspects of learning into consideration (Koole \& Ally, 2006; Koole, 2006). The FRAME model describes m-learning as a process resulting from the convergence of mobile technologies, human learning characteristics, and social interaction. Moreover, the FRAME model does not only outline the relationship between m-learning, personal learning capacities, and social interaction, but it also addressed contemporary pedagogical issues of information overload, knowledge navigation, and collaborative learning. In the FRAME model, m-learning experiences views as existing within the context of information. Within the context of information, the FRAME model is represented by a Venn diagram, in which showed three aspects of interests. The Venn diagram shows the conceptualization of the FRAME model (see Figure 1). The FRAME model includes three aspects, which are device usability aspect (D), learner aspect (L), and social aspect (S).

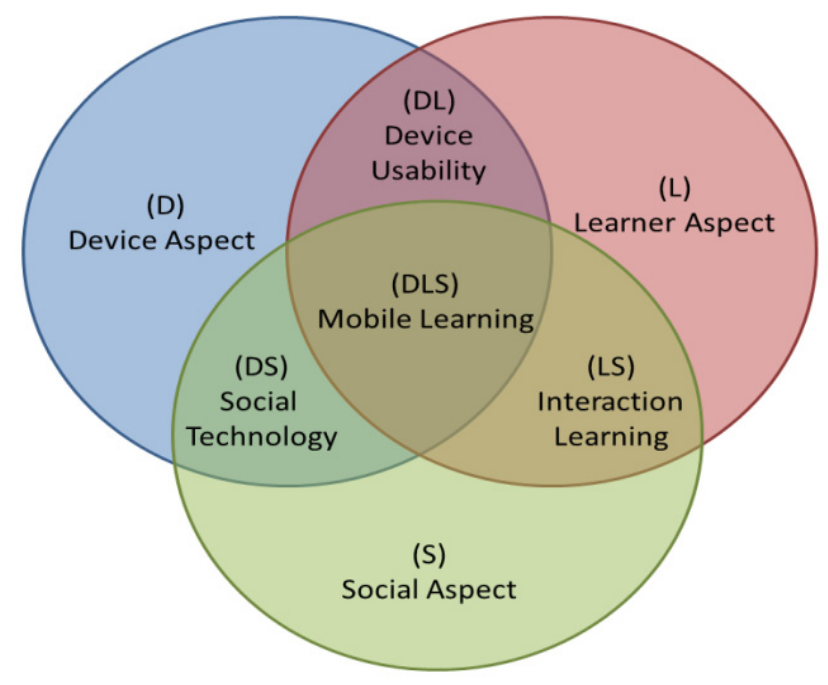

Figure 1. The FRAME model.

Second, this study focuses not only on formal learning, but also on informal learning. Marsick and Watkins (1990) defined formal learning as that which students typically learn in school. It is classroom-based and well-structured. Informal learning is vastly different from formal learning. It includes incidental learning that might occur in school, but not typically classroom-based or well-structured, and learners can fully control their learning. Informal learning might not be related to the formal curriculum, and it might be related to life experiences (Merriam, Caffarella, \& Baumgartner, 2012). The flexibility of informal learning is great and allows students to gain knowledge without instructors (Livingstone, 2001). Smith and Smith (2008) listed below the informal learning activities, such as reading books or magazine, watching videos, attending conferences, sharing in groups or oganizations, watching television, using software to gain the knowledge, and learning things from the Internet that is related to personal interests or helps develop personal skills.

\section{Methods}

This study collected qualitative data for analysis. To enlarge the full picture of the qualitative data 
collected, three qualitative data collection methods-pre-focus group interview, diary record, and post-interview - were being adopted. The reason of using these three research instruments to collect qualitative data is because triangulation is necessary to capture valid and reliable multiple and diverse realities when collecting qualitative data (Creswell \& Miller, 2000).

Table 1Table 1 showed that the proportion of students with the major of study in arts, business, engineering, and sciences. According to the ethical consideration, all of the interviewees are assigned to have a specific code. All codes had three digits. The first digit indicates student's major study—alphabet "A" represents that the student is studying in Arts, alphabet "B" represents in business, alphabet " $E$ " represents in engineering, and alphabet " $\mathrm{S}$ " represents in sciences. The second digit is " 0. " The third digit is the student's number. For example, "A01" refers to the first student studying in arts.

Table 1

The Population of Qualitative Data $(N=14)$

\begin{tabular}{lll}
\hline & & $N$ \\
\hline \multirow{2}{*}{ Gender } & Female & 7 \\
& Male & 7 \\
\hline \multirow{3}{*}{ Major of study } & Arts & 4 \\
& Business & 3 \\
& Engineering & 4 \\
& Sciences & 3 \\
\hline
\end{tabular}

Firstly was the pre-focus group interview. There were four times of pre-focus group interviews conducted in April of 2013. Each pre-focus group interview had three to four Guangzhou's university students to share their practices of using a mobile device in learning. Each group students studied similar major discipline. The pre-focus group interview was semi-structured and was conducted in Cantonese or Putonghua because some participants spoke Putonghua only. The pre-focus group interview took approximately one hour per session. All data were to be kept confidentially, and the interviews were being used for research purposes only. The interviews were transcribed and sent back to the interviewees for confirmation prior to review for analysis.

Secondly was the diary. To ensure the participants had written down their m-learning practices consistently and systematically, well-designed and structured diaries were given. Structured diaries provided an analytically focused data-gathering instrument that enabled researchers to collect data on every specific feature (Gibson \& Brown, 2009). Based on the FRAME model, the rationale of structured diary book was designed. All students needed to record their learning activities and interaction within four weeks into the structured diary book so that it could fairly reflect their m-learning activities. A total of 14 participants completed the activities in May of 2013. The diary data were being quantified for analysis. In the dairy record, six major m-learning activities, namely, discussion, reading/watching, searching, learning, recording, and sharing were recorded. The participants had to record their m-learning activities in four sections for four consecutive weeks. The four sections are the midnight section (00:00-06:00), morning section (06:00-12:00), afternoon section (12:00-18:00), and evening section (18:00-24:00). Therefore, the total timeslots are four timeslots per day $\times 28$ days (four weeks) $=112$ timeslots in the research period.

Lastly was the post-interview. After observing the four weeks' practices dairy record of the participants, it was found that different participants had different practices for using a mobile device to learn. Therefore, the 
purpose of the post-interview was to let the participants explain in detail why they chose the mobile devices to do those learning activities and the types of interaction. So, the researcher had an in-depth understanding of their participated in m-learning activities. Through the post-interview, it provided the opportunities to the interviewees to express their views and feel sophisticated, and the researcher could easily follow up the unexpected results or go deeper into the motivation of respondents and reasons for responding as they did (Kerlinger \& Lee, 1999). Prior to the review for analysis, the interviews were transcribed and sent back to the interviewees for confirmation.

\section{Findings and Discussion}

The purpose of this section is to present the qualitative findings in light of the FRAME model. For qualitative findings, all pre-focus group interviews, diary records, and post-interviews are transcribed for analysis. Through the analysis, learning practices, learning strategies, and characteristics of mobile devices for formal and informal learning under each aspect were found out.

\section{The Findings of the Device Aspect}

The device aspect refers to the physical, technical, and functional characteristics of a mobile device (Koole \& Ally, 2006; Koole, 2009). The interviewers responded that Guangzhou's university students agreed that bandwidth was the highest factor to affect learning. Five students agreed poor bandwidth affected their learning performance and the frame of mind. High and stable quality broadband can let them learn smoothly in the whole learning process. Hence, they preferred using Wi-Fi to access the Internet for m-learning, because Wi-Fi is not expensive and has the stable quality of accessing the Internet. Most of the university students may not afford the price of $3 \mathrm{G}$ or $4 \mathrm{G}$ because $3 \mathrm{G}$ or $4 \mathrm{G}$ is quite expensive in Guangzhou. As a result, they preferred using Wi-Fi to access the Internet in school, home, or hostel, and they wish more free Wi-Fi access point in public.

Guangzhou's university students agreed the screen size was the lowest factor to affect learning. Students B03 and E04 believed that reading through desktop is more comfortable than mobile device, because the screen size of desktop is larger than mobile device, but student E01 expressed that he did not want to stay in a fixed position for a long time to operate the computer. Portability is the power of mobile devices, but the weakness of mobile devices is that the screen is too small which limited the process of obtaining information, and the users could not read many characters in one page. Students B03, E01, and E04 commented that mobile devices are not suitable for long-time operation, because the battery could not support the power for long period, and the screen size is not suitable for long-time reading. They believed that desktop should be more suitable for long-time working, especially typing.

Figure 2 shows that $57 \%$ Guangzhou's university students supported that higher quality mobile devices may affect positive learning. They believed that using the higher-ranking mobile device is better for learning, and the value for money is the most concerned issue. Figure 2 also shows that $43 \%$ Guangzhou's university students supported that higher quality mobile devices may not affect positive learning. They disagreed that the higher-ranking mobile devices affected positive learning, because they believed that there were no differences between a high-quality mobile device and a low-quality mobile device, such as electronic reading. Students are concerned more for the content of an e-book rather than the quality of e-books. Most of them agreed that the speed of network connection is more important than the price of mobile devices. Hence, this study could not conclude that higher technical ranking mobile devices had a positive impact on m-learning. 


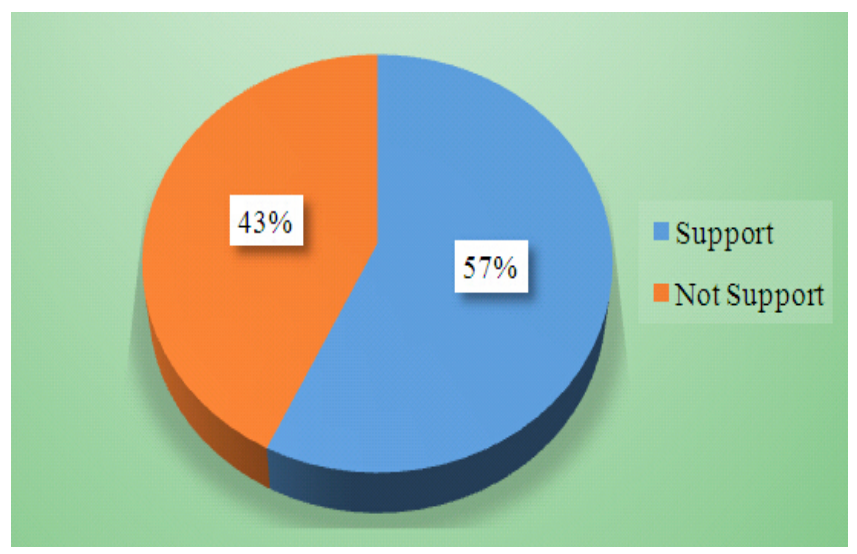

Figure 2. Percentages of supporting higher quality mobile devices affected positive learning.

\section{The Findings of the Learner Aspect}

The learner aspect refers how learners use what they already know and how they encode, store, and transfer information (Koole \& Ally, 2006; Koole, 2009).

Table 2Table 2 shows the diary findings of the percentages for formal and informal learning in the learner aspect of m-earning activities. It finds that Guangzhou's university students spend $62.4 \%$ of timeslot using mobile devices to read or watch for learning. Mobile reading or watching is the highest ranking m-learning activity. However, the percentages of formal learning and informal learning are $6.25 \%$ and $93.75 \%$ correspondingly. Clearly, the findings indicate that using a mobile device to read or watch for informal learning is the major practice of Guangzhou's university students. Moreover, the findings find that Guangzhou's university students spend $27.4 \%$ of timeslot using the mobile search function for learning. The percentages of formal learning and informal learning are $39.5 \%$ and $60.5 \%$. Although the percentage of informal learning is higher than the formal learning, the percentage gap between informal and formal learning is less than electronic reading. Then, the findings also find that Guangzhou's university students spend $12.7 \%$ of timeslot using mobile devices to learn. The percentages of formal learning and informal learning are $88.3 \%$ and $11.7 \%$ accordingly. The percentage of informal learning is lower than formal learning. Furthermore, the findings find that Guangzhou's university students spend $21.9 \%$ of their timeslot using the digital recording function of mobile devices for learning. Besides, the percentages of formal and informal learning are $37.8 \%$ and $62.2 \%$. The percentage of informal learning is higher than formal learning.

Table 2

Diary Findings of the Percentages for Formal and Informal Learning in the Learner Aspect of M-learning Activities

\begin{tabular}{lllr}
\hline M-learning activities & Diary findings (\%) & Learning type & $\%$ \\
\hline \multirow{2}{*}{ Electronic reading } & \multirow{2}{*}{62.4} & Formal & 6.25 \\
& & Informal & 93.75 \\
\hline \multirow{2}{*}{ Searching } & \multirow{2}{*}{27.4} & Formal & 39.5 \\
& & Informal & 60.5 \\
\hline \multirow{2}{*}{ Learning } & \multirow{2}{*}{12.7} & Formal & 88.3 \\
& & Informal & 11.7 \\
\hline \multirow{2}{*}{ Digital recording } & \multirow{2}{*}{21.9} & Formal & 37.8 \\
& & Informal & 62.2 \\
\hline
\end{tabular}


The strategies of electronic reading. For formal learning, students use mobile devices to read Websites, news, and books or watch movies for doing assignments. Students A04, B01, B02, and B03 read the recommended websites by their teachers. Students B01, E03, and S03 read news as to update their information in community or finance. Students A01 and S03 watch online movies to do assignments. Student A04 was interviewed and stated:

My teacher always requests me to do a book report. So, I downloaded e-books from the Internet to my smartphone for reading. The advantage is that I can download many e-books without purchase and read without place and time limitation. Moreover, I can search the keywords from e-books that improve my efficiency in reading.

Thus, students use mobile devices to read websites, news, and books or watch movies for study. Students B01 and S03 read the e-books recommended by their teachers, such as "STATA". Student S03 watches online movies for learning national geographic. Student B01 was interviewed and stated:

I read teaching materials in the lesson because my teachers upload teaching notes to the school's learning platform. Therefore, I downloaded notes to my smartphone and read during the lesson. So, no need to print and bring notes to my lesson.

Additionally, students watching online movies can learn professional computer software that assists them in doing assignments. Student B01 was interviewed and stated:

I watch online movies in learning business data analyze software "STATA" and computer software skills, such as editing online movies for assisting doing assignments. The advantage of watching online movies is that I can learn step by step. I watch online movies from smartphone and use the desktop to practice. This learning method can improve my learning performance.

For informal learning, students read Weibo or news to update daily knowledge or news. Besides, students read websites, news, and books or watch movies for gaining extensive knowledge for formal learning, such as financial knowledge, sciences, history, Chinese literature, etc.. Students B01 and B03 read websites for learning financial knowledge. Student S03 was interviewed and stated:

I watch online TV or movies for learning history. Although I am studying sciences, I have the interest to learn more deeply in Chinese history. My school cannot offer me to study Chinese history. Therefore, I watch online TV or movies to understand the Chinese history deeply.

The strategies of searching. For formal learning, students use mobile devices to search information, knowledge, or data for doing assignments. Six students expressed that they searched from Baidu professional knowledge Websites or China Knowledge Resources Integrated Database (CNKI) to acquire professional knowledge for studying or doing assignments.

Students use mobile devices to search learning researches, books, professional articles, papers, and learning Apps for study. Students B01, E01, and E04 search formal learning resources from Baidu, and students A03 and S01 search professional articles and papers. Student S02 was interviewed and stated:

I always search learning Apps from my smartphone, because most learning Apps are assisting me for my study. Moreover, the learning Apps are updated which can demonstrate the experimental results by graphs or animation.

Sometimes, students use mobile devices to search in the lessons. Students A03, A04, and S02 search during lessons. Students A03, A04, and S02 use mobile devices to search in the lesson when they do not understand the context in the lesson or would like to find out more extendable knowledge. Baidu professional 
knowledge Websites (http://baike.baidu.com) and CNKI (http://www.cnki.net) are the major searching platforms for formal learning.

For informal learning, students use mobile devices to search knowledge for solving daily life problems. Students A01 and A02 search knowledge for solving their daily life problems; students B01, B02, S02, and S03 search from Baidu websites to find the routes; and students B01, B02, S02, and S03 search from Baidu websites to find healthy problems. Six students search from Baidu websites to find out the solution of technical computer problems.

Ten students search books or information to enhance their knowledge of hobbies, such as movies, sports, singing, travels, technologies, and handcrafts. Student B01 was interviewed and stated:

I always use the Apps of Baidu websites in my smartphone to search the travel information on the streets. The smartphone became my good navigator on the street.

Student B02 was interviewed and stated:

I always search Baidu websites to find the updated information of handcrafts and search the Baiduzhidao to acquire updated information of sports.

The strategies of learning. For formal learning, mobile devices have roles of multi-functions and can be the learning tools in the lesson or out of lesson, because they can download different types of learning Apps for learning. Guangzhou's university students believed that mobile devices could be a tool of the translator. Students A03, E01, E02, E04, S01, and S02 mentioned that they always download different types of learning Apps (Safko, 2012), such as translation Apps to learn English. They always use mobile devices to translate vocabulary or sentence for study. Student A03 was interviewed and stated:

I always use mobile devices to check online dictionary in the lesson.

Student E01 was interviewed and stated:

Practicality, entertainment, and multi-functionality are the benefits of mobile devices.

Additionally, students E04, S01, S02, and S03 downloaded the Apps of scientific or engineering calculator into their smartphones for calculation in the lesson. Student E04 was interviewed and stated:

I download engineering equation Apps to find a solution. The benefits of downloaded the Apps are no need to bring a calculator and save time to search the equation from books.

For informal learning, students A01, A02, B02, and B03 use mobile devices to do the translation when reading foreign newspapers, magazines, or websites. Students B01, E02, and S01 use Apps of mobile devices for learning the knowledge of hobbies; students B03 and S03 do online assessments to assess knowledge standard of hobbies. Nine students downloaded and used the learning Apps to acquire the knowledge of hobbies. Student S03 was interviewed and stated:

I believe smartphone has become a powerful tool, and Apps can be expanded the functions of smartphone. I like to download different types of Apps for learning the knowledge of my hobbies.

The strategies of digital recording. For formal learning, students use mobile devices for data organization. Students B01, B03, A02, A04, E04, E03, and S02 took photos of teacher's handwriting in the lesson. Student E03 was interviewed and stated: 
I always use a smartphone to take photos during the lesson for capturing teacher's hand-written notes because my teacher's teaching speed is too fast. So, I use my smartphone to capture the notes on the blackboard. After photo shooting in the lesson, I rewrote the notes in my notebook for further study. I believed taking photos in the lesson is a good practice for study.

Student B02 was interviewed and stated:

I always use my smartphone to jot down important notes in the lesson. As comparing with using pen and paper notes to jot down important notes, using a smartphone to jot down notes is more flexible for editing. Digital notes can keep for a long time and convenient to edit. Smartphone allowed me to insert sentences or keywords into the middle of a paragraph. Also, important sentences could be highlighted for easy memory. After edited, records would be converted into different digital formats, such as Words and PowerPoint formats for the record. After the lesson, I use the edited notes for studying purpose or doing assignments. In the lesson, the table size for students is limited. Therefore, the size of the smartphone is an advantage to record or to edit notes because the smartphone is lighter and smaller than a notebook. So, the smartphone is the most suitable learning tool in the lesson.

Thus, students A01 and A02 prefer to store e-articles into mobile devices for study as it does not have time and location limitation. They can download lecturer's notes, webpages, and search result files into their mobile devices for study in any time and place.

Moreover, student E02 was interviewed and stated:

There are many Apps to help student's memory in China. I believed those Apps were the most useful tools, for examples, Towards (http://towords.com/) and Baicizhan (http://www.baicizhan.com) which could be downloaded to my smartphone and the Apps can frequently show the words on the smartphone for learning vocabulary. The Apps are free of charge but need to register on the website before using. I agreed those Apps could help students learn effectively and efficiently, if there are no Apps, I could not remember as much vocabularies as in a short period. If I have no assistance from a smartphone, I believed I need to spend more time to learn vocabulary and memorize the English words.

For informal learning, students B01, B02, B03, E02, E03, S01, S02, and S03 use mobile devices to record their daily life experiences for memorizing. Students A01 and A03 use mobile devices for diary recording; students A02, B02, and E03 also have the practices of using smartphone to record their personal diaries or to study notes. Moreover, student A02 was interviewed and stated:

I downloaded a famous Chinese App which is called Fenfen diary (http//:www.fenfenriji.com/) to record my daily life experience. I post the feeling by text, photo, and video to record my daily life. I believed the smartphone is a convenient tool for recording, because it does not have time and location limitation, and I could immediately record any sudden incident.

\section{The Findings of the Social Aspect}

The social aspect is the process of social interaction and cooperation (Koole \& Ally, 2006; Koole, 2009). Table 3 shows the percentages of formal and informal learning for the social aspect of m-learning activities. The findings find that the percentage of Guangzhou's university students using mobile devices for discussion learning is $23.7 \%$. The percentages of formal and informal learning are $14.1 \%$ and $85.9 \%$. On the other hand, it finds that Guangzhou's university students spend $13.2 \%$ of timeslot using mobile devices to share for learning. The percentages of formal learning and informal learning are $53.1 \%$ and $46.9 \%$. Obviously, the findings indicated that using mobile devices to discuss and share for formal and informal learning are the major practices of Guangzhou's university students.

In social aspect for formal and informal learning, this section lists out the m-learning strategies of Guangzhou's university students. 
For formal learning, types of assignment are the major factors of using mobile devices. Six students expressed that they formed the QQ group, and four students indicated that they formed the email group for sharing and discussion to do group projects. Students, S01 was interviewed and stated:

I joined the sciences competition with my classmates. So, I need to discuss frequently with my group mates. Using mobile devices can send or receive messages on time.

Sometimes, they invited teachers to add to the QQ or email group as a channel of consultation in giving opinion and instruction for doing projects. Additionally, teachers can keep track of the records and status of the projects and monitor each student's contribution. Student A01 formed a group in QQ private group and invited classmates and teachers to discuss an assignment. QQ private group is a popular online social networking platform in mainland China. The user can form a private group for discussing and sharing information. Student A01 was interviewed and stated:

If there is no QQ group, I cannot achieve the same learning performance.

Therefore, mobile devices can allow users to write down details with an explanation to all group mates to ensure all group mates understand what and how should do. Moreover, all email system has functions of tracing records for conversion. Therefore, group mates should clearly understand the process and status in completing the project.

For informal learning, students mostly use QQ or email for sharing and discussing with common interests to border their horizons. Six students expressed that they would like to share with friends or classmates on online social networking platforms, such as Weibo for interesting news or hobbies. Weibo is not only a platform for students to share news or articles, and also an online social networking platform for learning different kinds of knowledge, such as sports, politics, music, beauty and make-up skills, etc. (Bugeja, 2006; Green \& Hannon, 2007; Jones, 2002; Mazer, Murphy, \& Simonds, 2007; Mazer, Murphy, \& Simonds, 2009; Safko, 2012; Vockley, 2007). Weibo is not only text-based, but also posted audio and video onto the platform. Therefore, students can read or watch different types of media to gain knowledge.

Table 3

The Percentages of Formal and Informal Learning for the Social Aspect of M-learning Activities

\begin{tabular}{llll}
\hline M-learning activities & Diary findings (\%) & Learning type & $\%$ \\
\hline \multirow{2}{*}{ Discussion } & \multirow{2}{*}{23.7} & Formal & 14.1 \\
& & Informal & 85.9 \\
\hline \multirow{2}{*}{ Sharing } & \multirow{2}{*}{13.2} & Formal & 53.1 \\
& & Informal & 46.9 \\
\hline
\end{tabular}

\section{Conclusion}

This study provides many m-learning strategies for Guangzhou's university students for formal and informal learning. Students believed that mobile devices acted as the role of multi-functions learning tools, such as reading, searching, and recording. Furthermore, mobile devices are important learning tools when doing the assignment for formal learning, because mobile devices are useful for cooperative and collaborative learning. For example, students use QQ group or email group for sharing and discussion when doing group projects. Sometimes, they invite teachers to join their QQ group for online discussion. Mobile devices can 
allow users to write down details with an explanation to all group mates to ensure all group mates understand what and how should do.

Figure 3 shows the percentages for formal and informal learning from diary record. It found that the percentage of formal and informal learning were $28 \%$ and $72 \%$. Therefore, it illustrated that the percentages of Guangzhou's university students using mobile devices for informal learning was higher than formal learning. Banks (2007) indicated the percentage of university students' formal learning was $8 \%$. However, this study found that Guangzhou's university students using mobile devices for formal learning was $28 \%$. Therefore, it can be concluded that mobile devices have a positive effect to university students on formal learning.

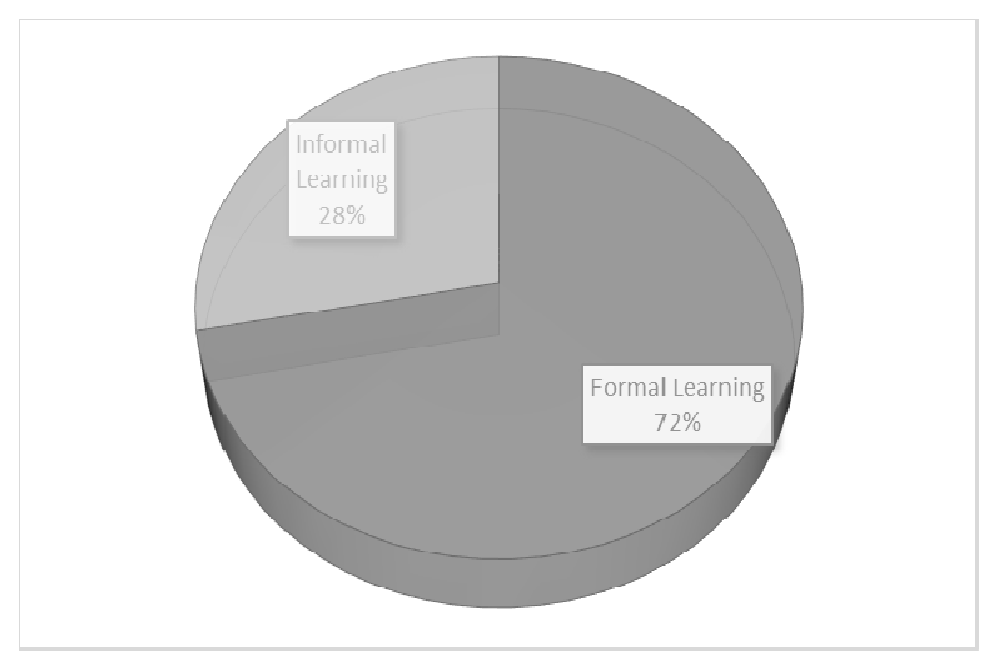

Figure 3. Percentages for formal and informal learning.

Figure 4 shows the percentages for formal and informal learning on each m-learning activity from diary records. It seems that the percentages of learning and sharing for formal learning are higher than informal learning. Searching and digital record have around $40 \%$ for formal learning whereas electronic reading and discussion are the fewest.

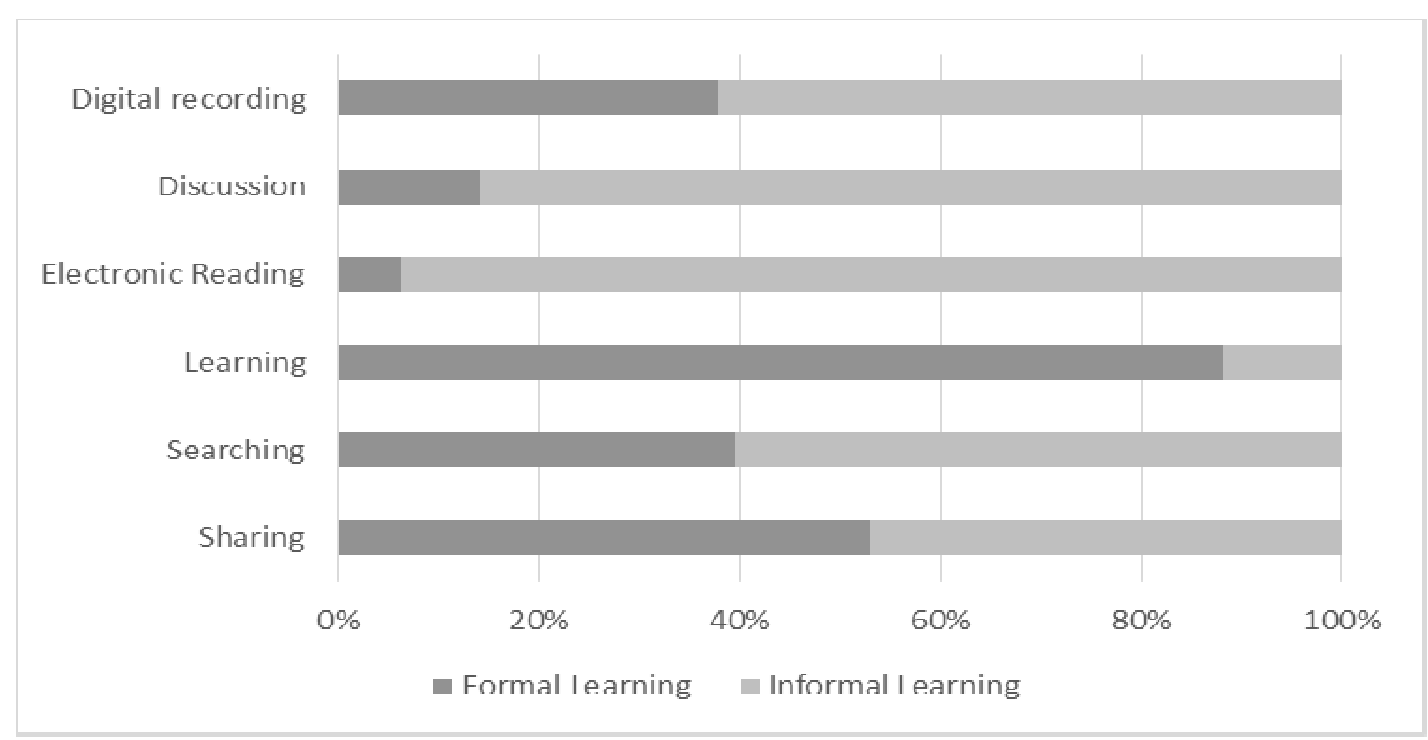

Figure 4. Percentages for formal and informal learning on different m-learning activities. 
For the pedagogy level, this study provides two recommendations. First is integrating social networking into traditional e-learning platform. Traditional e-learning platform might not fulfill existing university students' learning practices. They expected integrating social networking into traditional e-learning platform. For example, university lecturers might set up personal Weibo for the students to comprehend the updated learning information. In the Weibo, lecturers might post articles, news, and teaching schedule for students to follow. Therefore, students might check the learning status anytime and anywhere. Teaching resources, such as PowerPoints, notes, teaching videos, and past papers are the properties of the university. So, it was suggested to post those resources into traditional e-learning platform. This could be mentioned on the Weibo for students to understand.

Second is that teachers might become facilitators who have the role to facilitate students' learning. Student-centered learning should be the trend in the world in the university. This study ensures that mobile devices should be the effective and efficient learning devices for students' learning. Therefore, teachers should use the strength of mobile devices to facilitate students' learning, such as designing learning activities by using mobile devices for students' learning. Moreover, teachers may also design learning assessment in using mobile devices for students' self-learning.

\section{References}

Banks, J. A. (2007). Learning in and out of school in diverse environments: Life-long, life-wide, life-deep. LIFE Center, University of Washington, Stanford University, and SRI International.

Börner, D., Glahn, C., \& Specht, M. (2009). Mobile informal learning. Presentation for The Education in the Wild: Contextual and Location-Based Mobile Learning in Action Workshop at the STELLAR Alpine Rendez-Vous, November 30 to December 3, 2009, Garmisch-Partenkirchen, Germany.

Bugeja, M. J. (2006). Facing the Facebook. The Chronicle of Higher Education, 52(21), C1.

Chen, Y. Q. (2013). The investigation of adults for using mobile to learn. Distance Education in China, 19, 47-52.

Creswell, J. W., \& Miller, D. L. (2000). Determining validity in qualitative inquiry. Theory Into Practice, 39(3), 124-130.

Fan, C. X. (2012). SWOT analysis for mobile library. Library and Information Committee of Zhejiang Universities and Colleges, 2.

Gibson, W., \& Brown, A. (2009). Working with qualitative data. London, U.K.: Sage.

Green, H., \& Hannon, C. (2007). Their space: Education for a digital generation. London, U.K.: Demos.

Helen, F., \& Peng, Y. W. (2013). Mobile learning in higher education: Moving towards a framework for efficacy and sustainability. Distance Education in China, 17, 16-24.

Huang, J. J., Yang, S. J., Huang, Y., \& Hsiao, I. Y. (2010). Social learning networks: Build mobile learning networks based on collaborative services. Educational Technology \& Society, 13(3), 78-92.

Jones, S. (2002). The Internet goes to college: How students are living in the future with today's technology. Retrieved from http://www.pewinternet.org/files/old-media/Files/Reports/2002/PIP_College_Report.pdf.pdf

Kerlinger, F. N., \& Lee, H. B. (1999). Foundations of behavioral research. Fort Worth, T.X.: Harcourt \& Brace.

Koole, M. L. (2006). The framework for the rational analysis of mobile education (FRAME) model: An evaluation of mobile devices for distance education (Unpublished thesis, Athabasca University).

Koole, M. L. (2009). A model for framing mobile learning. Mobile Learning: Transforming the Delivery of Education and Training, 25-47.

Koole, M., \& Ally, M. (2006). Framework for the rational analysis of mobile education (FRAME) model: Revising the ABCs of educational practices. In proceedings of The International Conference on Networking, International Conference on Systems and International Conference on Mobile Communications and Learning Technologies (ICN ICONS MCL'06) (pp. 216-216). Mauritius: IEEE. doi:10.1109/ICNICONSMCL.2006.103

Li, G. Y., Ma, L., Ning, Y. W., \& Li, G. M. (2012). The study of automobile learning model in cloud learning platform. Modern Educational Technology, 21(11), 76-79.

Liu, J., Yu, S., \& Ran, M. (2008). Research on the communicative mobile English learning model. In Proceedings of the 5th IEEE International Conference on Wireless, Mobile, and Ubiquitous Technology in Education (WMUTE) 2008 (pp. 60-64), Beijing, China. 
Livingstone, D. W. (2001). Adults' informal learning: Definitions, findings, gaps and future research (NALL working paper No. 21, OISE/UT, Toronto).

Marsick, V. J., \& Watkins, K. E. (1990). Informal and incidental learning in the workplace. New York, N.Y.: Routledge.

Mazer, J. P., Murphy, R. E., \& Simonds, C. J. (2007). I'll see you on "Facebook": The effects of computer-mediated teacher self-disclosure on student motivation, affective learning, and classroom climate. Communication Education, 56(1), 1-17.

Mazer, J. P., Murphy, R. E., \& Simonds, C. J. (2009). The effects of teacher self-disclosure via Facebook on teacher credibility. Learning, Media and Technology, 34(2), 175-183.

Merriam, S. B., Caffarella, R. S., \& Baumgartner, L. M. (2012). Learning in adulthood: A comprehensive guide. San Francisco, C.A.: John Wiley \& Sons.

Naimie, Z., Siraj, S., Abuzaid, R. A., \& Shagholi, R. (2010). Hypothesized learners' technology preferences based on learning style dimensions. Tojet, 9(4).

Safko, L. (2012). The social media bible: Tactics, tools, and strategies for business success (3rd ed.). Hoboken, N.J.: John Wiley \& Sons.

Sharples, M., Taylor, J., \& Vavoula, G. (2005). Towards a theory of mobile learning. Paper presented at mLearn 2005, Cape Town, South Africa.

Smith, M. C., \& Smith, T. J. (2008). Low-education adults' participation in informal learning activities: Relationships with selected demographic characteristics. Adult Basic Education and Literacy Journal, 2(2), 67-73.

Sun, Y., Zhang, X., \& Wang, Q. H. (2013). The investigate of mobile learning for high school students. Computer Education, 21, 53-56.

Tang, Z. W., Wang, L. Y., Dai, L. L., \& Zhao, N. (2014). The feasibility study of mobile learning in rural areas-A study based on FRAME model. e-Education Research, 35(1), 38-44.

Traxler, J. (2007). Defining, discussing and evaluating mobile learning: The moving finger writes and having writ... The International Review of Research in Open and Distance Learning, 8(2), 511.

Vockley, M. M. (2007). Creating \& connecting: Research and guidelines on online social and educational networking. Alexandria, V.A.: National School Boards Association.

Wang, J. Q., Xu, C. J., Zhong, B. C., \& Li, Y. (2013). Design and implementation of mobile resources learning package. e-Education Research, 5, 13.

Yang, W. Y. (2013). The investigate of mobile learning framework under the rationale of lifelong learning. Distance Education in China, 7, 78-82.

Zhang, L., Wang, J. H., Zhang, J., \& Di, J. Q. (2010). The application of mobile learning in high school education. Computer Education, 6, 34-37.

Zywno, M. S., \& Waalen, J. K. (2002). The effect of individual learning styles on student outcomes in technology-enabled education. Global Journal of Engineering Education, 6(1), 35-44. 